\title{
POTENSI INTERAKSI OBAT AMLODIPIN PADA PASIEN HIPERTENSI DI SALAH SATU PUSKESMAS KABUPATEN SUMEDANG
}

\author{
Ani Anggriani ${ }^{1}$, Eva Kusumahati ${ }^{2}$, Irfan Hilmi Multazam ${ }^{3}$ \\ ${ }^{1,2,3}$ Universitas Bhakti Kencana
}

Email korespondensi: ani.anggriani@bku.ac.id

\begin{abstract}
ABSTRAK
Penyakit hipertensi masih menjadi salah satu masalah kesehatan utama di Indonesia, tujuan penelitian ini adalah untuk mengetahui profil penggunaan obat amlodipin dan potensi interaksi obat serta hubungan jumlah obat dengan kejadian interaksi obat di Puskesmas Sukasari Kabupaten Sumedang periode Juli-Desember 2019. Penelitian ini dilakukan secara observasional, dengan metode deskriptif. Pengambilan data didapat dari dari rekam medik pasien secara retrospektif, pengolahan data dilakukan menggunakan software drug interaction checker. Data yang diperoleh sebanyak 112 pasien. Analisis data dilakukan secara kuantitatif dan kualitatif. Hasil penelitian menunjukkan bahwa dari 112 pasien terdapat jumlah pasien yang berpotensi mengalami interaksi obat sebanyak 82 orang $(73 \%)$. Interaksi obat yang terjadi berdasarkan jenis interaksi farmakodinamik $62 \%$ dan farmakokinetik $38 \%$, berdasarkan tingkat keparahan moderate sebesar $62 \%$ dan minor $38 \%$. Potensi interaksi obat paling banyak amlodipin dan hidrochlorthiazide berefek sinergis sebanyak 56\%, serta amlodipin dan kalsium karbonat berefek antoganis sebanyak $20 \%$.
\end{abstract}

Kata kunci : Interaksi Obat, Hipertensi, Amlodipin 


\title{
THE INTERACTION POTENCY OF AMLODIPINE HYPERTENSION PATIENTS IN A IN A PUBLIC HEALTH CENTRE IN DISTRIC OF SUMEDANG
}

\begin{abstract}
Hypertension is still a main health problem in indonesia, the purpose of this research is to know the profile of the antihypertensive agent and the interaction potency of the drugs and the relation between the amount of the drugs towards the interaction occurrence in public health centre of sukasari in district of sumedang by the period of July-December 2019. This was observational research with descriptive method. The data collection was performed using drug interaction checker software. There are data of 112 patients. The analysis was performed quantitatively and qualitatively. The results showed that out of 112 patients, 82 patients (73\%) had the potential to experience interaction. Drug interactions that occurred based on the type of pharmacodynamic interaction $62 \%$ and pharmacokinetics $38 \%$, based on moderate severity of $62 \%$ and $38 \%$ minor. The most potential drug interactions are amlodipine and hydrochlorthiazide with a synergistic effect of 56\%, and amlodipine and calcium carbonate with an antogenic effect of $20 \%$.
\end{abstract}

Keywords : Drug Interaction, Hypertension, Amlodipine

\section{PENDAHULUAN}

Hipertensi merupakan penyakit yang terjadi karena adanya peningkatan nilai tekanan darah sistolik dan diastolik lebih dari 140/90 mmHg pada dua kali pengukuran dengan selang waktu lima menit dalam keadaan tenang. Hipertensi yang tidak terdeteksi dan berlangsung dalam jangka waktu lama serta mendapat pengobatan yang tidak memadai, dapat menimbulkan penyakit lainnya seperti penyakit jantung koroner gagal ginjal, dan stroke. Jumlah pasien hipertensi dengan tekanan darah tidak terkontrol terus meningkat. Oleh karena itu perlu partisipasi semua pihak baik dokter, pemerintah, maupun masyarakat agar penyakit hipertensi dapat terkendali. (Kemenkes.RI, 2014). Hipertensi dapat dibedakan menjadi 2 jenis, yaitu hipertensi primer (esensial) dan hipertensi sekunder. Penyebab penyakit hipertensi tidak diketahui, sedangkan hipertensi sekunder disebabkan oleh penyakit lain seperti penyakit ginjal, endokrin, jantung dan gangguan ginjal. Menurut JNC VII, hipertensi terjadi jika tekanan darah sistolik (TDS) dan atau tekanan darah diastolik (TDD) $\geq 140 / 90 \mathrm{mmHg}$ pada dua kali pengukuran dalam waktu yang berbeda (Tarigan et al., 2018).

Data World Health Organization (WHO) tahun 2015 menunjukkan bahwa penyakit hipertensi diderita oleh sekitar 1,13 Miliar orang di dunia, 
artinya 1 dari 3 orang di dunia terdiagnosis hipertensi. Setiap tahunnya jumlah pasien hipertensi terus meningkat, pada tahun 2025 diperkirakan akan ada sekitar 1,5 Miliar orang yang terkena hipertensi, dan diperkirakan ada 9,4 juta orang meninggal setiap tahunnya akibat hipertensi dan komplikasinya. (Kemenkes.RI \& Arianie, 2019). Berdasarkan data Riskesdas 2018 prevalensi penyakit hipertensi naik dari $25,8 \%$ menjadi 34,1\%. Kenaikan tersebut berhubungan dengan pola hidup yang tidak sehat, antara lain kurangnya aktivitas fisik, merokok, konsumsi minuman beralkohol, serta kurangnya konsumsi buah dan sayur (Kemenkes.RI \& Arianie, 2019).

Interaksi obat-obat didefinisikan sebagai pengaruh farmakokinetik atau farmakodinamik obat satu sama lain di mana suatu zat mempengaruhi aktivitas suatu obat, sehingga efeknya meningkat atau menurun, atau menghasilkan efek baru yang tidak diproduksi sendiri. Masalah interaksi obat pasti akan muncul, oleh karena itu bijaksana untuk belajar tentang interaksi tersebut sehingga dapat dikelola secara efektif (Pamu et al., 2017).

Berdasarkan panduan manajemen hipertensi oleh Seventh Report of the Joint National Committe on Prevention, Detection, Evaluation, and Treatment of High Blood Pressure (JNC 7), pasien hipertensi memerlukan dua obat atau lebih untuk mencapai tujuan tekanan darah $(<140-90 \mathrm{mmHg}$ atau $130-80$ mmHg pada pasien hipertensi dengan CKD atau Diabetes) (Chobanian,
Bakries, \& HR Black, n.d.). Namun pada pasien hipertensi yang sedang menggunakan terapi antibiotik golongan makrolida harus hati-hati dalam pemberian obat hipertensi untuk pasien tersebut, karena obat hipertensi golongan makrolida dapat berinteraksi dengan obat hipertensi golongan calsium channel bloker contohnya pemberian erythromicin + verapamil, hal tersebut dapat terjadi karena calsium channel blocker dimetabolisme oleh enzim CYP3A4 sedangkan Eritromisin (antibiotik makrolida) merupakan inhibitor CYP3A4, sehingga kadar CCB dalam darah dapat meningkat ke level yang berbahaya jika enzim tersebut dihambat yang dapat menyebabkan pasien menjadi hipotensi (Mizranita, Pramudhita \& Maret 2014). Berdasarkan survei, penggunaan obat antihipertensi menunjukkan bahwa dari dari 9 jenis obat hipertensi yang digunakan dengan total penggunaan 253 item obat, penggunaan amlodipin sebanyak 112 item obat $(44,27 \%)$, hidroklorotiazid 44 item obat $(17,39 \%)$, captopril 39 item obat $(15,41 \%)$, Furosemid 24 item obat $(9,49 \%)$ candesartan 23 item obat $(9,09 \%)$, Propanolol 4 item Obat (1,58\%), Diltiazem 3 item Obat $(1,19 \%)$ Bisoprolol 2 item obat $(0,79 \%)$ dan Lisonopril 2 item obat $(0,79 \%)$. Amlodipin merupakan obat antihipertensi golongan calsium channel blocker yang pengunaannya sebagai monoterapi atau dikombinasikan dengan golongan obat lain seperti diuretik, ACE-inhibitor, ARA II atau beta bloker dalam penatalaksanaan hipertensi. Berdasarkan permasalahan 
tersebut maka dilakukan penelitian ini untuk mengetahui potensi interaksi obat hipertensi golongan calsium channel blocker yang terjadi pada pasien hipertensi (Tandililing et al., 2017)

\section{METODE PENELITIAN}

Penelitian ini merupakan penelitian observasional yang dilakukan secara retrospektif dengan melihat lembar rekam medis dari pasien hipertensi. Pengumpulan data dilakukan dengan menggunakan teknik purposive sampling yaitu teknik penentuan sampel dengan pertimbangan tertentu. Kemudian dilakukan penetapan kriteria pasien dan kriteria obat. Kemudian data yang diperoleh akan dianalisis menggunakan software drugs interaction checker untuk melihat kategori interaksi yang terjadi, selanjutnya dilihat mekanisme yang terjadi menggunakan pustaka yang sah, seperti pada buku stockley's drug interactions $9^{\text {th }}$ edition. Pengolahan data dilakukan dengan analisis deskriptif. Lalu dilakukan pengambilan kesimpulan dan saran.

\section{Rancangan Penelitian}

Penelitian ini menggunakan jenis penelitian observasional dengan metode deskriptif dan pengambilan data dilakukan secara retrospektif dari lembar resep di rekam medis pasien yang menderita penyakit hipertensi yang telah diberi terapi obat amlodipin, rancangannya terdiri dari :

1. Penetapan Kriteria Obat, Kriteria obat yang dianalisis interaksinya pada penelitian ini yaitu obat amlodipin
2. Penetapan Kriteria Pasien Kriteria pasien pada penelitian ini yaitu meliputi 2 kriteria diantaranya:

a. Kriteria Inklusi, yaitu semua pasien rawat jalan, jenis kelami laki-laki dan perempuan yang yang menderita hipertensi dengan penggunaan obat amlodipin tunggal ataupun kombinasi

b. Kriteria Eksklusi, yaitu semua pasien rawat jalan yang menderita hipertensi tanpa penggunaan obat amlodipin

3. Sumber Data Penelitian, Sumber data penelitian didapatkan dari data lembar rekam medis berupa: Identitas pasien dan resep pengobatan obat amlodipin. Data yang diambil adalah data retrospektif yang berasal dari lembar rekam medis bulan JuliDesember 2019 di salah satu Puskesmas Kabupaten Sumedang.

4. Penetapan Sampling Penelitian, Pasien yang didiagnosa hipertensi di Puskesmas Sukasari Kabupaten Sumedang periode Juli-Desember 2019, diperoleh sampling data pasien sebanyak 112 pasien yang terdiri dari perempuan dan laki-laki dewasa.

\section{Metode Pengolahan data}

a. Memeriksa data (editing) yang dimaksud memeriksa atau proses editing adalah memeriksa data hasil pengumpulan data. Hasil dari lembar rekam medis yang telah dicatat kemudian diperiksa kembali kelengkapannya untuk 
mengetahui bahwa data yang terkumpul sudah cukup baik .

b. Tabulasi data (Tabulating) yang dimaksud yaitu menyusun dan mengorganisir data sedimikian rupa, sehingga akan dapat dengan mudah untuk dilakukan penjumlahan, disusun dan disajikan dalam bentuk tabel atau grafik. Pada penelitian ini data yang telah dianalisi akan di sajikan dalam bentuk tabel yang berisi kategori interaksi, drug-drug interaction, mekanisme, dan manifestasi klinik.

c. Analisis Data Analisis dilakukan secara kuantitatif dan kualitatif:

- Analisis kuantitatif merupakan analisa untuk mengetahui obat amlodipin yang berpotensi terjadi interaksi dengan obat lainnya menggunakan software Drug Interaction Checker.

- Analisis Kualitatif merupakan analisis mengenai jumlah interaksi obat yang terjadi berdasarkan mekanisme, tingkat keparahan, dan manifestasi klinis. Kemudian masing-masing dianalisa dan dibuat dalam bentuk presentase.

\section{Pengambilan Kesimpulan dan} Saran, Hasil analisis dengan perhitungan statistik dari jumlah kejadian potensi interaksi obat amlodipin dengan obat lain dibagi total kejadian potensi interaksi obat sehingga dapat diambil kesimpulan mengenai potensi interaksi obat amlodipin pada pasien hipertensi di salah satu Puskesmas di kabupaten Sumedang.

\section{HASIL DAN PEMBAHASAN}

Hasil penelitian ini terdapat jumlah resep yang terdapat di rekam medis sebanyak 112, satu lembar resep untuk satu pasien sesuai jumlah pasien yang didiagnosa hipertensi di Puskesmas Sukasari Kabupaten Sumedang periode Juli-Desember 2019. Hasil analisis kejadian potensi interaksi obat dari 112 pasien terdapat 82 kejadian potensi interaksi dengan hasil sebagai berikut :

Tabel 1 Jenis interaksi dan tingkat keparahan potensi interaksi obat Antihipertensi

\begin{tabular}{|c|c|c|c|c|c|c|c|c|c|}
\hline \multirow{3}{*}{ Obat 1} & \multirow{3}{*}{ Obat 2} & \multicolumn{4}{|c|}{ Jenis Interaksi } & \multicolumn{4}{|c|}{ Tingkat Keparahan } \\
\hline & & \multicolumn{2}{|c|}{$\begin{array}{c}\text { Farmakoki } \\
\text { netik }\end{array}$} & \multicolumn{2}{|c|}{ Farmakodinamik } & \multicolumn{2}{|c|}{ Moderat } & \multicolumn{2}{|c|}{ Minor } \\
\hline & & $\Sigma$ & $\%$ & $\Sigma$ & $\%$ & $\Sigma$ & $\%$ & $\Sigma$ & $\%$ \\
\hline \multirow{7}{*}{ Amlodipin } & Kaptopril & & & 5 & $6 \%$ & & & 5 & $6 \%$ \\
\hline & Hidrochlorthiazid & & & 46 & $56 \%$ & & & 46 & $56 \%$ \\
\hline & Natrium Diclofenac & & & & & & & & \\
\hline & $25 \mathrm{mg}$ & 4 & $5 \%$ & & & 4 & $5 \%$ & & \\
\hline & Asam Mefenamat & 9 & $11 \%$ & & & 9 & $11 \%$ & & \\
\hline & Dexametasone & 1 & $1 \%$ & & & 1 & $1 \%$ & & \\
\hline & Aspirin & 1 & $1 \%$ & & & 1 & $1 \%$ & & \\
\hline
\end{tabular}




\begin{tabular}{ccccccccc} 
Kalsium Karbonat & 16 & $20 \%$ & \multicolumn{1}{c}{16} & $20 \%$ \\
\hline Jumlah & & $\mathbf{3 8}$ & & & & & & \\
& $\mathbf{3 1}$ & $\mathbf{\%}$ & $\mathbf{5 1}$ & $\mathbf{6 2 \%}$ & $\mathbf{3 1}$ & $\mathbf{3 8 \%}$ & $\mathbf{5 1}$ & $\mathbf{6 2 \%}$ \\
\hline
\end{tabular}

(Sumber: Data rekam medik Puskesmas Sukasari Kabupaten Sumedang)

Tabel 1 di atas menunjukkan bahwa kejadian potensi interaksi obat antihipertensi berdasarkan jenis interaksi yang paling banyak terjadi adalah interaksi farmakodinamik sebesar $\quad 62 \% \quad(51 \quad$ kejadian $)$ dibandingkan dengan interaksi farmakokinetik sebesar $38 \% \quad(31$ kejadian). Sedangkan berdasarkan tingkat keparahan, terdapat $38 \%$ atau sebanyak 31 kejadian interaksi bersifat minor dan $62 \%$ atau 51 kejadian interaksi bersifat moderat. Interaksi obat secara farmakokinetik dengan tingkat keparahan moderat yang paling banyak ditemukan adalah kombinasi amlodipin dengan NSAID yaitu natrium diclofenac $25 \mathrm{mg}$, interaksi kedua obat ini ditemukan sebanyak 4 kasus. Efek dari kombinasi tersebut adalah menurunnya efek hipertensi amlodipin. Berdasarkan mekanisme NSAID yang dapat menghambat sintesis prostaglandin yang tidak hanya menyebabkan efek antiinflamasi namun juga dapat menyebabkan vasokontriksi pada afferent ginjal yang menyebabkan penurunan aliran darah menuju ginjal sehingga menyebabkan teraktifasinya sistem renin angiotensin (Fournier et al., 2012). Namun penelitian yang dilakukan oleh (White, 2009) menyebutkan bahwa pemberian obat hipertensi golongan CCB bersamaan dengan NSAID tidak menyebaban peningkatan tekanan darah pada pasien hipertensi karena didasarkan pada mekanisme CCB yang tidak berhubungan dengan kadar natrium sehingga dapat mengontrol tekanan darah pasien.

Tabel 2. Kejadian Potensi Interaksi Obat Amlodipin Serta Efek dan Manajemen yang Harus Dilakukan

\begin{tabular}{|c|c|c|c|c|c|c|}
\hline $\begin{array}{c}\text { Drug } \\
1\end{array}$ & Drug 2 & $\begin{array}{c}\text { Tingkat } \\
\text { Keparahan }\end{array}$ & Kejadian & $\%$ & Efek & Manajemen \\
\hline & Kaptopril & Minor & 5 & $6 \%$ & $\begin{array}{l}\text { aditif, } \\
\text { sinergisme }\end{array}$ & $\begin{array}{l}\text { Lakukan } \\
\text { pemantauan } \\
\text { tekanan } \\
\text { darah }\end{array}$ \\
\hline & $\begin{array}{l}\text { Hidrochlorthi } \\
\text { azid (HCT) }\end{array}$ & & 46 & $\begin{array}{l}56 \\
\%\end{array}$ & $\begin{array}{l}\text { aditif, } \\
\text { sinergisme }\end{array}$ & $\begin{array}{l}\text { Lakukan } \\
\text { pemantauan } \\
\text { tekanan } \\
\text { darah }\end{array}$ \\
\hline & $\begin{array}{l}\text { Natrium } \\
\text { Diclofenac } \\
25 \mathrm{mg}\end{array}$ & Moderate & 4 & $5 \%$ & $\begin{array}{l}\text { Penurunan } \\
\text { efek } \\
\text { antihipertensi }\end{array}$ & $\begin{array}{l}\text { Lakukan } \\
\text { pemantauan } \\
\text { tekanan } \\
\text { darah }\end{array}$ \\
\hline Amlod & $\begin{array}{l}\text { Asam } \\
\text { Mefenamat }\end{array}$ & & 9 & $11 \%$ & $\begin{array}{l}\text { Penurunan } \\
\text { efek }\end{array}$ & $\begin{array}{l}\text { Lakukan } \\
\text { pemantauan }\end{array}$ \\
\hline
\end{tabular}




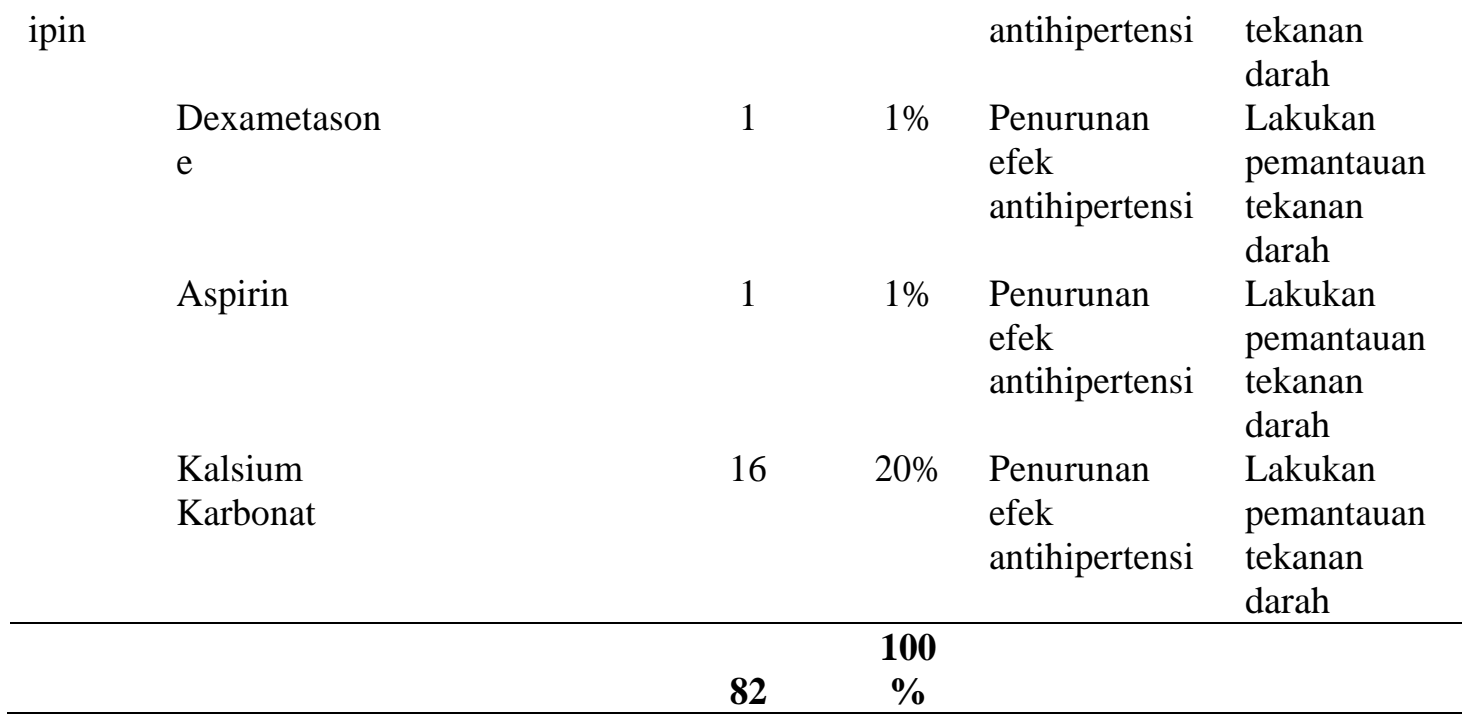

(Sumber: Data rekam medik Puskesmas Sukasari Kabupaten Sumedang)

Berdasarkan tabel 2 di atas diketahui bahwa kejadian potensi interaksi obat amlodipin dan hidrochlorthiazid merupakan kejadian yang banyak terjadi yaitu terjadi sebanyak 46 kejadian, namun interaksi tersebut tidak bersifat merugikan. Amlodipin ditemukan efektif (13/1 mmHg menurunkan tekanan darah) ketika ditambahkan dengan hidrochlorthiazid (Baxter,2010). Selain itu terjadi pula potensi interaksi obat antihipertensi dengan obat lain yaitu amlodipin dan Kalsium Karbonat terjadi sebanyak 16 kejadian. Efek dari kombinasi tersebut berupa penurunan efek amlodipin oleh Kalsium Karbonat, amlodipin pada awalnya berfungsi untuk memperlambat pergerakan kalsium untuk masuk ke dalam sel jantung dan dinding arteri kemudian arteri menjadi rileks sehingga tekanan darah ke jantung dapat diturunkan, namun adanya asupan Kalsium Karbonat dapat menurunkan efektivitas CCB karena terjadi penjenuhan saluran kalsium oleh adanya penumpukan kalsium. Hal yang bisa dilakukan untuk mengatasi efek dari interaksi dari kedua obat ini adalah tidak memberikan kedua obat secara bersamaan. Penggunaan amlodipin dan Kalsium Karbonat harus diberikan jeda waktu sekitar 3-4 jam. Selain itu harus dilakukan pemantauan agar tidak terjadi efek samping yang merugikan (Salfitri et al., 2017).

\section{SIMPULAN}

Kesimpulan dari penelitian ini adalah : Interaksi obat hipertensi yang paling banyak terjadi yaitu amlodipin dengan golongan obat diuretik (Hidrochlorthiazide) sebanyak 56\% yang berefek sinergis, serta amlodipin dengan kalsium karbonat sebanyak $20 \%$ berefek antagonis yang dapat menurunkan efek obat amlodipin.

\section{UCAPAN TERIMAKASIH}

Pada kesempatan ini, peneliti ingin mengucapkan terima kasih kepada

https://doi.org/10.33759/jrki.v1i1.108 
berbagai pihak yang telah membantu terwujudnya penelitian ini :

1. Dekan Fakultas Farmasi Unisersitas Bhakti Kencana.

2. Kepala Puskesmas Sukasari Sumedang

\section{DAFTAR PUSTAKA}

Faturrahman, M. (2013). Analisis Potensi Interaksi Obat dan Manifestasi Klinik Resep Anak di Apotek Bandung Analysis of Potential Drug-Drug Interactions and Its Clinical Manifestation of Pediatric Prescription on 2 Pharmacies in Bandung. Jurnal Farmasi Klinik Indonesia, 2(3), 121-126.

Baxter, K. (2006). Stockley's Drug Interactions, 8th Edition. Annalsof Pharmacotherapy, 40(6), 12191219. https://doi.org/10.1345/aph.1g691

Baxter, K. (2010). Stockley's drug interactions: a source book of interactions, their mechanisms, clinical importance and management. Choice Reviews Online, 48(03), 48-1222-48- 1222. https://doi.org/10.5860/choice.481222

Fournier, J. P., Sommet, A., Bourrel, R., Oustric, S., Pathak, A., LapeyreMestre, M., \& Montastruc, J. L. (2012). Non-steroidal antiinflammatory drugs (NSAIDs) and hypertension treatment intensification: A population-based cohort study. European Journal of Clinical Pharmacology, 68(11), 1533-1540.

https://doi.org/10.1007/s00228012-1283-9.

Kemenkes.RI. (2014). Pusdatin
Hipertensi. Infodatin, (Hipertensi), $1-$ 7. https://doi.org/10.1177/109019817 400200403

Kemenkes.RI, \& Arianie, P. (2019). Hipertensi penyakit paling banyak diidap masyarakat. 2017-2020.

Krause, T., Lovibond, K., Caulfield, M., McCormack, T., \& Williams, B. (2011). Management of hypertension: Summary of NICE guidance. BMJ (Online), 343(7821). https://doi.org/10.1136/bmj.d4891

Pamu, S., Singh, T., Ravi, S., \& Ranganayakulu, S. V. (2017). Evaluations of Drug-Drug Interactions in Hypertensive Patients in Secondary Care Hospital. IOSR Journal of Pharmacy and Biological Sciences, 12(02), 45-50. https://doi.org/10.9790/30081202044550

Riskesdas, 2018. (2018). Hasil Utama Riskesdas 2018.

Salfitri, Nurmainah, \& Yuswar, M. A. (2017). Kajian Interaksi Obat Antihipertensi pada Pasien Hemodialisis Di Rumah Sakit Umum Yarsi Pontianak Tahun 2017.

Tandililing, S., Mukaddas, A., \& Faustine, I. (2017). Profil Penggunaan Obat Pasien Hipertensi Esensial di Instalasi Rawat Jalan Rumah Sakit Umum Daerah I Lagaligo Kabupaten Luwu Timur Periode JanuariDesember Tahun 2014. GALENIKA Journal of Pharmacy, 3(1), 49-56.

Tarigan, A. R., Lubis, Z., \& Syarifah, S. (2018). Pengaruh Pengetahuan, 
Sikap Dan Dukungan Keluarga Terhadap Diet Hipertensi Di Desa Hulu Kecamatan Pancur Batu Tahun 2016. Jurnal Kesehatan, 11(1), 9-17. https://doi.org/10.24252/kesehatan. v11i1.5107

White, W. B. (2009). Defining the Problem of Treating the Patient with Hypertension and Arthritis Pain. American Journal of Medicine, 122(5 SUPPL.), S3-S9. https://doi.org/10.1016/j.amjmed.2 009.03.002

Widjaya, N., Anwar, F., Laura Sabrina, R., Rizki Puspadewi, R., \& Wijayanti, E. (2019). Hubungan Usia Dengan Kejadian Hipertensi di Kecamatan Kresek dan Tegal Angus, Kabupaten Tangerang. YARSI Medical Journal, 26(3), 131.

https://doi.org/10.33476/jky.v26i3. 756 